\title{
The Structure of State Health Agencies: A Strategic Analysis
}

\author{
By: Eric W. Ford, W. Jack Duncan, Peter M. Ginter
}

Ford, E. W., Duncan, W. J., and Ginter, P. M. (2003). The Structure of State Health Agencies: A Strategic Analysis. Medical Care Research and Review. 60 (1), pp. 31-57.

Made available courtesy of Sage Publications: http://www.sagepub.com/

*** Note: Figures may be missing from this format of the document

\begin{abstract}
:
Leaders in public organizations are adopting many private sector management practices to control costs and increase efficiency. Nowhere is this more evident than among state health agencies. State health agencies were encouraged to change the way they operate by the 1988 Institute of Medicine (IOM) report on The Future of Public Health. This report portrayed public health as being in disarray. To address major deficiencies identified by the IOM study, some public health leaders have reevaluated their environments, reconfigured their organizations, and adopted a strategic mindset. The purpose of this research is to explore the various organizational configurations of state health agencies. Replicating methods used in studies of private sector organizations, five distinct strategic configurations or archetypes were identified. This comprehensive public health agency taxonomy will assist future researchers in analyzing public health organizations' environments, structures, and strategies.
\end{abstract}

Keywords: strategy; configurations; public health; management

\section{Article:}

Public health has enjoyed a long history in the United States, and the successes have been remarkable. Advances in areas such as securing safe air and water, the elimination of smallpox and polio, and the protection of the public's health in general have increased dramatically the quality and length of life in the United States during the 20th century. However, the shift in focus from eradicating or minimizing infectious diseases to health promotion and prevention has created new organizational challenges for health care agencies.

Health care agencies' measures of success are difficult to identify because of their prevention focus. For example, cancer, the second leading cause of death today, is actually several diseases arising from any combination of behavioral and environmental elements. Because chronic illnesses have a range of outcomes and interventions, identifying which public health programs are effective is complex. Surgeon General Designate Jocelyn Elders $(1995,2293)$ stated that "Public Health is poorly understood-perhaps because when it is effective, nothing happens."

Adding to the difficulty of understanding public health agencies has been the rise of managed care. Insurers simultaneously competing and collaborating with state and local health agency efforts adds to the complexity of evaluating the effectiveness of public health. Although most of the managed care- public health agency interaction occurs at the local level, "The role of state health departments in managing, evaluating, and contributing to these alliances should not be overlooked" (Halverson et al. 1997, 115).

Public organizations have responded to the changing environment in a variety of ways. To collaborate and/or sometimes compete with private sector organizations, state health agencies began adopting private sector strategies and structures. For example, the 1988 Institute of Medicine (IOM) report, The Future of Public Health, stated,

This study was undertaken to address the growing perception among the IOM membership and others concerned with the health of the public that this nation has lost sight of its public health 
goals and has allowed the system of public health activities to fall into disarray.... Unfortunately, the findings of this committee confirm the concerns that led to this study. (P. 1)

The publication of this report generated a substantial amount of interest in the way state health agencies were perceived and evaluated (C. A. Miller, Moore, and Richards 1993; Scutchfield, Beversdof, et al. 1997).

The IOM's view of public health management in 1988 was not positive. The implications of the report were that public health agencies were improperly structured and poorly managed. Robert Rubin $(1988,161)$, a member of the committee, dissented from this assertion, stating, "I do not believe that there is one correct structure of state government that will lead to the answer of the public health dilemma ... the committee's recommendations do not appear to be based on solid evidence, either empirical or practical."

The IOM's (1988) report identified and made recommendations in terms of health departments' core functions: assessment, policy development, and assurance. A subsequent survey of agency leaders by the Association of State and Territorial Health Officers (ASTHO) found that the health officers generally agreed with the IOM's that these three areas were critical public health activities (Scott, Tierney, and Waters 1990). Despite agency leaders' concurrence with the IOM's recommendations, by 1996 little progress had been made in increasing core function capabilities in the departments (Scutchfield, Beversdof, et al. 1997).

The pace of change has continued to accelerate and concerns continue to be raised so that the struggle to meet community needs and expectations is as great as ever. "In recognition of these new challenges, the IOM conducted an 18-month DHHS interagency-sponsored study that considered how best to assure the health of the public in the 21st century" (IOM 2002). The stated goal of the task force is congruent with the contribution of this article, "To describe a new, more inclusive framework for assuring population-level health that can be effectively communicated to and acted upon by diverse communities" (IOM 2002).

\section{NEW CONTRIBUTION}

The question of how to structure organizations for mission accomplishment has been an integral part of strategy research for many years. Research on strategy and structure has involved, among other things, developing a priori typologies (Doty and Glick 1994). The present study examines strategy and structure using empirically derived configurations rather than simple classifications of organizations into separate groups. In accomplishing this objective, environmental, organization structure, and strategy-making variables have been adopted from previous studies of profit-oriented corporations and health service organizations.

The configurations yielded by this analysis give a general picture of how health care agencies' environments, structures, and strategies combine to form a discreet number of gestalts. By exploring organizational "states [i.e., gestalts], change must be described as rather dramatic transformation-the leap from one state to another" (Mintzberg and Lampel 2001, 42). This is particularly important in state health agencies because their scope of activities is very wide and no single metric of success, or dependent variable, can be used to determine their success. Therefore, more systemwide changes are generally required to make a significant impact on a community's overall health status. The results of this study serve as an initial indicator of the current states that agencies have achieved — either through intended or emergent strategies.

This study also provides two additional new contributions to the literature on organizational configurations in health care. First, it extends the configuration approaches used in management research into the government sector of health care agencies. Second, the configuration results provide a more complete description of state health agencies' structures than the current superagency division versus independent health agency dichotomy used in previous research (e.g., IOM 1988; Public Health Foundation 1986). Taken together, these two advances provide health agency researchers, their leaders, and stakeholders a new perspective on agencies' strategic, structural, and environmental characteristics. 


\section{PREVIOUS HEALTH AGENCY RESEARCH}

Various authors have recognized the value of the IOM report although relatively few studies have directly attempted to measure the state of public health practice in the United States. Of the seven studies identified, three focused on local health departments (LHDs) (Centers for Disease Control and Prevention 1994; Handler and Turnock 1996; Scutchfield, Hiltabiddle, et al. 1997). Studies of LHDs confirmed the perceived importance but neglected status of the policy development area of public health. Another study (Wall 1998) measured the relationship between the states and LHDs primarily on the basis of revenue and funding.

Wall (1998) confirmed the existence of different organizational types based on more than the commonly used geographic and demographic characteristics. In particular, two dimensions, local control and local revenue, were used to form a 2 × 2 matrix for examining state health department similarities. To illustrate, it was found that Wisconsin and Texas occupied the quadrant corresponding to high local control and high local revenue. However, these two states were very different relative to demographic characteristics. On the other hand, Texas and Florida had similar populations, immigration issues, and large urban centers but were in opposite quadrants. Therefore, organizational configurations based on environmental and managerial characteristics may be more comprehensive than either geographic or revenue structure typing alone.

The remaining studies (Scott, Tierney, and Waters 1990; Scutchfield, Beversdof, et al. 1997; Scutchfield, Hiltabiddle, et al. 1997) were more directly related to the IOM report and public health at the state level. Scott, Tierney, and Waters (1990) were the first to conduct a complete census based on the IOM's vision of how public health should be structured. Their findings are informative when compared with the later replication by Scutchfield, Beversdof, et al. (1997). Among the three core functions, rates of agencies engaging in assessment and assurance activities were generally unchanged during the 7-year interval between the two studies. However, the percentage of state health agencies actively engaging in policy development declined from 72 percent to 49 percent during the same period. This implies that a formal policy development function was absent in approximately half of the states. The Scutchfield, Hiltabiddle, et al. (1997) survey was conducted in a blind fashion; therefore, it is impossible to determine which states most recently engaged in policy development. Nevertheless, it raises the issue that while nearly every leader considers policy development activities important, progressively fewer agencies are actually doing them.

One possible explanation for the declining involvement in policy development is that the rapidly changing environment has outstripped agencies' abilities to engage in effective strategic planning. "We live in a complex, interconnected global society in which there are many threats to, and opportunities to improve, the public's health" (Stoto, Abel, and Dievler 1996, 9).

For example, the competencies required for policy development are much the same as those required for strategic planning and include collecting and interpreting data relating to public health issues, summarizing the data in terms of policy options, and the development of policy implementation plans including goals and objectives. The most recent reassessment of the effect of The Future of Public Health (IOM 1988) was conducted by the IOM itself, using a series of discussions among a panel of experts (Stoto, Abel, and Dievler 1996). Their findings supported the initial report's conclusions, expanded on them, and identified the importance of building alliances with community stakeholders, managed care organizations in particular-all of which are strategic initiatives.

A review of the research on state health agencies since the initial 1988 IOM report leads to three conclusions. First, public health is a complex set of systems, and one-dimensional classifications do not meaningfully explain organizational differences. Second, there is a desire among practitioners and academicians to better understand and improve the public health mechanisms of the 50 United States. Finally, the importance of strategic management concepts has gained a significant place in the public health literature. Therefore, applying established management research techniques to better understand how public agencies are structured and set priorities is an important next step. 


\section{ORGANIZATIONAL CONFIGURATIONS AND TAXONOMIES}

There are two primary approaches to classifying organizations: typologies and taxonomies. Typologies normatively describe how organizations can be classified based on deductive reasoning. Typologies are defined as "conceptually derived interrelated sets of ideas" (Doty and Glick 1994, 232). Organizational attributes are hypothesized a priori, and unique combinations are formed to build a set of predicted types. The empirical effectiveness of such typologies (McKelvey 1975; Meyer, Tsui, and Hinings 1993; D. Miller and Friesen 1986a, 1986b; Shortell and Zajac 1990) and their value to theory development has been debated extensively (Doty and Glick 1994; Hambrick 1984; Sutton and Staw 1995; Weick 1995). Existing typologies such as Miles and Snow's (1978) competitive strategies or Porter's (1980) generic strategies have been used to study a variety of settings including health care (Shortell and Zajac 1990).

The taxonomic approach involves selecting a set of organizations and empirically deriving a method of classification. Rich $(1992,761)$ stated that a taxonomy "is more than a simple classification of items into separate groups: it is a specific classification scheme that expresses the overall similarity between organisms in a hierarchical fashion." Previous research has used financial measures such as net profit or return on investment to array configurations, usually from most to least successful. The most important feature of any configuration is determining the intended purpose of the organizations being analyzed (Fleishman and Quaintance 1984; Law, Wong, and Mobley 1999).

The value of using configurations in qualitative research is evident in several respects. One indication of this value is The Academy of Management Journal's Special Issue dedicated to the configuration approach (Meyer, Tsui, and Hinings 1993). The enduring worth of configurations research is also manifested in D. Miller's (1986) article on the subject, which won the Strategic Management Journal's best paper prize in 1995 (Bettis 1996), nearly a decade after its publication.

Despite the significant contribution of taxonomy research to the management literature, there is still a need for further refinement and replication. As D. Miller $(1996,506)$ stated, "For all its promise, the literature on configurations remains underdeveloped, and my Strategic Management Journal piece represented a very preliminary and tentative attempt to further it along." Therefore, this research incorporated several methodological innovations designed to further advance the field.

\section{RESEARCH DESIGN AND METHOD}

There were two phases to the research. First, the sample of agencies to be studied was identified and data were gathered. Next, the agencies were scored and sets of archetypal agencies were empirically derived using the methodology developed by D. Miller and Friesen (1984) and later replicated by Reeves (1996) in the health care industry. The major constructs used to configure the different state health agencies were environmental factors, organizational characteristics (structure), and strategy-making qualities. The variables that describe each construct are defined in the appendix.

\section{SAMPLE IDENTIFICATION AND DATA SCORING}

One difficulty in studying public health is that the functions reside in a variety of departments within each state's government. Therefore, a method for identifying the correct department within each state was necessary. The selection criterion employed in this research was to select the cabinet-level leader that had public health in her or his agency.

The potential population of organizations was limited to agencies from the 50 United States. United States territories were omitted because of the varying degree of federal involvement in their programs. The District of Columbia was also omitted because it represents just one city and has extensive federal oversight.

\section{DATA SCORING}

The configuration analysis section of this research replicates and extends the work done by D. Miller and Friesen (1984) and Reeves (1996). The previous studies' variables have been altered in two respects. First, the 
cues to scorers for each variable were tailored to the selected setting — state health departments. Second, the scoring of the two organizational dimension variables was combined in a nonlinear method as suggested by Simon (Anderson 1999; Daft 1992; Simon 1996). The configuration analysis is discussed in three sections. First, the data sources are described. Next, the variable scoring methodology is developed. Finally, interrater reliability is addressed.

\section{Data sources}

Studying state health agencies rather than private organizations allowed for an innovation in configuration research. State agencies make public large amounts of raw data relating to the organizations' activities relative to private companies. Therefore, the expert raters in this study analyzed information produced by the organizations.

Previous configuration researchers had their scorers evaluate case studies or articles written by third parties not directly connected to either the organization under review or the study itself. This study's scorers directly evaluated documents originating from the subject organizations. Each type of data source has potential strengths and weaknesses. Information generated by the organizations themselves may be manipulated to create positive impressions or, worse still, pictures that do not reflect objective reality. Alternatively, case writers may serve as a medium that filters misleading rhetoric from the organization. Another potential bias related to case writers is that they may engage in favorable selection, choosing either more or less successful organizations to illustrate a particular phenomenon. This study did sample a substantial portion of the agencies engaged in health care activities, thus mitigating the potential selection bias problem.

The amounts of data available from each state varied greatly. Some states had strategic plans, mission statements, budgets, annual reports, leaders' speeches, Healthy People goals, and other relevant documents available directly on their Internet sites. Other states had smaller amounts of formal reporting. Four different attempts were made to gather the desired materials. First, state agencies' Web sites were reviewed and available reports were gathered. However, most states lacked enough information on the Internet to complete the proposed research. Therefore, when listed on the site, the public relations officer was contacted via e-mail. The items specifically requested were strategic plans, budgets, annual reports, Healthy People 2000 and 2010 goals, and organization charts. If the public relations director failed to reply electronically, they were contacted by mail. Finally, information was solicited directly via telephone. This method produced a substantial amount of data. States were deemed to have provided inadequate information if two reviewers determined that the information necessary to score any variable was absent. Ultimately, 41 states, or 82 percent, provided adequate information to be included in the configuration analysis.

To detect any nonresponse bias, demographic (U.S. Census Bureau 2000) and Health Resources and Services Administration [HRSA2001] grant characteristics of the sample and nonrespondent states were compared. Five demographic statistics germane to public health issues were drawn from the 2000 census and examined: (1) persons aged 65 years and older (percentage); (2) white persons, not of Hispanic/Latino origin (percentage); (3) median household income, 1997 model-based estimation; 4) children below poverty, 1997 model-based estimation; and (5) persons per square mile. Four funding measures based on the HRSA's total grants for fiscal year 1999 were compared between the two groups: (1) health professional training, (2) maternal and child health, (3) primary health care, and (4) rural health care.

Four of the five demographic measures' $t$-tests were not significant $(p>.5)$. The comparison of racial composition, based on the percentage of white persons not of Hispanic or Latino origin, was significant ( $p$ $<.05)$. Nonrespondent states had significantly larger white populations ( 82.9 percent) than the sample (74.3 percent). With respect to HRSA grant activity, none of the $t$-tests was significant $(p>.24)$. Given that only one of the nine public health measures compared differed significantly between the respondent and nonrespondent states, no systematic response bias is inferred. 


\section{Variables}

This research replicates previous work; therefore, comparable criteria for variable selection and scoring were employed. First, the variables common to D. Miller and Friesen (1984) and Reeves et al. (in press) were retained where possible. In the interest of parsimony and statistical power, variables that failed to differentiate organizations in previous research were either eliminated or combined with similar measures (see the appendix for a full description of variables). ${ }^{1}$ Second, the scoring technique used in previous research was broadened to include more raters. Each aspect of the variable development and scoring are discussed.

Three of the four categories originally used by D. Miller and Friesen (1984) and Reeves (1996) correspond to the categories found in the public health literature and were used in this research. One category, financial measures of success (e.g., return on investment, return on assets, and stock price), was not used because it did not have any direct counterpart in the public health setting.

Variables were coded in three ways: (1) continuous, (2) combined to form new measures, or (3) on a 7-point scale. There was only one continuous variable: tenure of the leader measured in months. The primary investigator compiled the variables related to leader's tenure, organizational span, and number of levels in the organizational hierarchy. The remaining variables were scored on a scale ranging from 1(much lower in a characteristic than other agencies) to 7 (had much more of the characteristic than other organizations) by multiple raters.

State health agencies publish a wide variety of documents in varying quantities. Few, if any, states create and make available every type of communication. In addition, information related to any particular variable could be described in an abstract manner. Similar to the previous configuration research using cases, it was necessary to employ an interpretive content analysis methodology using expert raters. As D. Miller and Friesen (1984, 270) explained, "To measure environmental dynamism, it was impossible in many instances to obtain information on the exact nature of price, technological, consumer-taste, and source of supply dynamism." Most states' documents provided information on a few of these items but not others. It was the raters' task to interpret the information provided and translates it into numerical scores. Therefore, it was necessary to have only one general scale for each of the concepts of interest.

\section{Interrater reliability}

Twelve raters were used to score the state agencies in a 1-day session. All raters had at least a master's degree in a health-related field (Master of Health Administration, Masters in Public Health [MPH], or health-focused Master of Business Administration [MBA]). A week before the session, each rater was given copies of an article on configurations in health care, a scoring sheet, and a practice state agency. The primary researcher met with each scorer individually to review their practice scoring and answer any questions. All of the practice scores were discarded to eliminate any influence bias, and some minor clarifications were made to the scoring sheet.

Because all scoring was intended to be relative, each scorer reviewed three randomly selected states before actually scoring them. As an initial measure of reliability, the reviewers were given one of three test states to analyze so that multiple rater comparisons could be made at that point. By using an intraclass correlation coefficient, it is possible to determine the amount of agreement among raters (Cronbach's alpha) and the significance of the correlation (Nichols 1998; $F$ statistic). The three sets of raters all had alphas greater than 60 $(.6023, .6060$, and .8390$)$. The $F$ statistics for the average intraclass correlation were all significant at the $p<.05$ level (.029, .0053, and .001, respectively).

Pedhazur and Schmelkin (1991) pointed out that standards of reliability vary, depending on the nature of the research. Nevertheless, their examples of adequate explanatory power fall between the .5 for exploratory research and .7 where high amounts of agreement are required. Therefore, alphas greater than .6 for each set of raters were deemed adequate for the purpose of this study, which was largely exploratory. Furthermore, this procedure produces a measure of absolute agreement, which is a higher expectation than the adjacency of scores 
used in previous work (D. Miller and Friesen 1984; Reeves, Duncan, and Ginter in press). Therefore, given that the statistics on the test states were reliable, especially under the stringent test assumptions, and because a second round of training took place after the initial test, the remainder of the sample was scored. The overall kappa statistic was .865 and significant at $p<.001$. This level of agreement exceeds the standard .60 value for kappa statistic that indicates a high degree of interrater reliability. Allowing for differences of 2 or less, the raters were in agreement 92.01 percent of the time.

\section{Taxonomy development method}

The taxonomy of state agencies was derived through cluster analysis, an iterative partitioning method. Aldenderfer and Blashfield $(1984,47)$ described the process as follows: "K-mean passes, also referred to as the 'nearest centroid sorting pass' and the 'reassignment pass,' simply involve the reassignment of cases to the cluster with the nearest centroid." The number of clusters generated is determined a priori in this method.

Every possible set of clusters from two to eight was considered. Beyond eight groupings, only clusters containing a single agency could be disaggregated at the margin. The configuration that yielded five clusters was selected for four reasons. First, it maximized the number of clusters with multiple members and eliminated any outliers or singleton clusters. Second, the distribution of variables that separated the clusters was relatively balanced. Third, the variables that were grouped together in each cluster had face validity. For example, the variables centralization of strategy-making power and delegation of operating authority, when extreme, were generally signed in opposite directions. Although these two constructs need not always be related inversely, it is the logical paradigm. Fourth, the $F$ statistics for the five-cluster solution, although heuristic, were as good as or better than any other configuration or set of configurations.

\section{RESULTS}

Table 1 shows the means, standard deviations, minimum values, maximum values, and the cluster analysis $F$ statistic for all agency configuration variables. By comparing the descriptive statistic of this study to the previous research of D. Miller and Friesen (1984) and Reeves (1996),13 of the 21 variables' scores fall between those of D. Miller and Friesen and Reeves. With respect to the variables' scores that differed from previous research, they were generally lower.

In the past, state health agencies have either been considered so idiosyncratic as to defy classification or have been dichotomized into superagencies or freestanding agencies (IOM 1988). Neither of these approaches allows for meaningful consideration of how one agency may compare with another. The analysis done in this project, based on environmental, organizational structure, and strategy-making variables, provides a first look into which state agencies share meaningful attributes. Illustrative examples are provided in each description, using direct quotes from agency leaders when available. See Table 2 for variables' mean scores by configuration.

The variables with the highest $F$ statistics not only served to differentiate the clusters, they also loaded positively into one particular group. Therefore, that cluster (strategy minded agencies), serves as a starting point in the description of clusters. Subsequent groups are taken in order of their scores on the four most significant variables.

\section{CONFIGURATION 1: FLEXIBLE AGENCIES IN UNPREDICTABLE ENVIRONMENTS}

Nine of the organizations, or about 22 percent, were classified as Flexible Agencies in Unpredictable Environments (see Table 3). This configuration had a relatively high standard deviation (0.7996) and mean (3.4024) of distances from the cluster's center, indicating that the members were more heterogeneous than other clusters (Harrigan 1985). Relatively high scores on dynamism and heterogeneity indicate that these organizations inhabit unpredictable environments. Coupled with the focus on service innovation, adaptation, and futurity of planning, which requires flexible organizational structures, the large variability within this group is not unexpected. Finally, their low reliance on precedents demonstrates a willingness to move in new directions. 
Compounding the difficulty of managing internal challenges are unusual or unique external environments (heterogeneity). Florida, which scored a five on heterogeneity and a seven on dynamism, faced a situation in which the population has grown between 20 percent and 80 percent each decade since 1920 (Brooks 1999).

TABLE 1 Variable Means and Standard Deviations for Configuration

\begin{tabular}{lrrrrr}
\hline Variable & M & SD & Minimum & Maximum & F Statistic \\
\hline Dynamism & 4.5 & 1.23 & 1.5 & 7.0 & $5.266^{* *}$ \\
Heterogeneity & 4.1 & 0.89 & 2.0 & 6.5 & $2.630^{*}$ \\
Munificence & 4.4 & 1.19 & 1.5 & 6.5 & $5.408^{* *}$ \\
Scanning & 4.5 & 1.31 & 1.0 & 6.5 & $14.772^{* *}$ \\
Delegation & 4.6 & 1.34 & 2.0 & 6.5 & $4.432^{* *}$ \\
Centralization & 4.5 & 1.22 & 2.0 & 7.0 & $3.717^{*}$ \\
Resource & 4.3 & 1.20 & 2.0 & 7.0 & $10.246^{* *}$ \\
Tenure (months) & 31.1 & 31.29 & 0.4 & 135.0 & $9.407^{* *}$ \\
Control & 4.9 & 1.14 & 2.0 & 7.0 & $11.748^{* *}$ \\
Communication & 4.5 & 0.93 & 1.0 & 7.0 & 1.122 \\
Differentiation & 4.3 & 0.84 & 2.5 & 7.0 & 2.086 \\
Technocratization & 4.3 & 1.46 & 1.0 & 7.0 & $6.541^{* *}$ \\
Hierarchy $(n)$ & 4.0 & 1.43 & 2.0 & 9.0 & \\
Span $(S)$ & 5.5 & 2.19 & 2.6 & 12.0 & \\
log $n$ & 0.9 & 0.308 & 0.3 & 1.6 & $3.268^{*}$ \\
Innovation & 3.9 & 1.12 & 1.0 & 6.0 & $19.284^{* *}$ \\
Adaptiveness & 4.5 & 1.29 & 1.0 & 6.5 & $15.662^{* *}$ \\
Integration & 4.4 & 1.06 & 2.0 & 6.5 & $8.594^{* *}$ \\
Consciousness of analysis & 4.8 & 1.43 & 1.0 & 6.5 & $7.478^{* *}$ \\
Multiplexity & 4.6 & 1.05 & 1.0 & 6.5 & $8.831^{* *}$ \\
Futurity & 5.0 & 1.46 & 1.0 & 7.0 & $4.694^{* *}$ \\
Precedents & 4.3 & 1.20 & 2.0 & 6.5 & $13.787^{* *}$ \\
\hline Note & & & & & \\
\hline
\end{tabular}

Note: The F-test should be used only for descriptive purposes because the clusters have been chosen to maximize the differences among cases in different clusters.

${ }^{*} p<.05 .{ }^{* *} p<.01$.

Furthermore, a large amount of this growth came through immigration of elderly persons, low-income individuals, and people from other countries. In addition, the state's subtropical climate and large standing bodies of water create health threats not present in most other parts of the country.

Despite these limitations, or perhaps because of them, Florida is very adaptive and willing to innovate. The state received national recognition for the success of its KidCare program in 1999 (Brooks 2000). Using creative advertisements and taking an interagency approach, the team won the Davis Productivity Award for their program. The team approach may also have benefited from the flat hierarchy that Florida uses to organize its divisions.

\section{CONFIGURATION 2: CENTRALIZED AND STABLE}

Five agencies (12 percent) clustered together and were labeled Centralized and Stable. The measures of centrality, mean distances from the center and standard deviation, indicated that the group members were the most homogeneous of any configuration.

Senior managers were powerful in this configuration, supported by well-trained staffs, and had the necessary resources available. Two states in particular, New Hampshire and Vermont, seemed to enjoy relatively munificent environments, and all the states lacked dynamism. From a strategy-making perspective, they had the second highest average scores on innovation, adaptation, consciousness of analysis, and multiplexity of decision making. This pattern of scoring is consistent with slow incremental change being led by secure executives. 
It is not surprising that Rhode Island and Vermont's health agencies should be highly centralized. Rhode Island's small geographic area and population lend themselves to such an organizational design. Vermont is larger but not so large that a central agency cannot respond to problems. The primarily rural and suburban distribution of people does not create large enough population centers to warrant sizable local agencies. The two Southern states in the cluster, Alabama and Mississippi, are highly centralized for similar reasons.

TABLE 2 Variable Means by Cluster

\begin{tabular}{|c|c|c|c|c|c|}
\hline \multirow[b]{2}{*}{ Variable } & \multicolumn{5}{|c|}{ Cluster } \\
\hline & 1 & 2 & 3 & 4 & 5 \\
\hline Dynamism & 4.8 & 3.4 & 4.9 & 3.9 & 2.5 \\
\hline Heterogeneity & 4.3 & 3.8 & 4.4 & 4.0 & 2.5 \\
\hline Munificence & 5.1 & 5.1 & 4.3 & 4.1 & 1.8 \\
\hline Scanning & 5.2 & 4.5 & 5.1 & 3.1 & 1.5 \\
\hline Delegation & 3.8 & 4.4 & 5.2 & 4.4 & 2.5 \\
\hline Centralization & 4.4 & 5.3 & 4.0 & 4.9 & 6.5 \\
\hline Resource & 5.2 & 5.7 & 3.9 & 3.9 & 2.3 \\
\hline Tenure & 13.9 & 83.8 & 23.3 & 44.7 & 13.5 \\
\hline Control & 5.9 & 5.3 & 4.7 & 4.4 & 2.0 \\
\hline Communication & 4.7 & 4.8 & 4.7 & 4.2 & 4.0 \\
\hline Differentiation & 4.3 & 3.6 & 4.3 & 4.4 & 5.5 \\
\hline Technocratization & 4.8 & 6.0 & 4.0 & 3.6 & 1.5 \\
\hline Hierarchy & 3.3 & 3.9 & 4.5 & 3.5 & 4.0 \\
\hline Span & 5.9 & 5.0 & 5.1 & 7.1 & 5.7 \\
\hline Innovation & 5.2 & 3.8 & 3.8 & 2.8 & 1.5 \\
\hline Adaptiveness & 5.6 & 5.0 & 4.5 & 3.2 & 1.5 \\
\hline Integration & 4.7 & 4.8 & 4.8 & 3.5 & 2.0 \\
\hline Analysis & 5.2 & 5.3 & 5.2 & 3.1 & 2.8 \\
\hline Multiplexity & 5.2 & 5 & 4.7 & 3.5 & 2.5 \\
\hline Futurity & 5.4 & 5.4 & 5.1 & 3.3 & 3.5 \\
\hline Precedents & 2.7 & 4.9 & 4.4 & 5.2 & 5.8 \\
\hline LogSpan & 0.7 & 0.9 & 1 & 0.7 & 0.8 \\
\hline
\end{tabular}

Note: Cluster 1 = Strategy Minded Agencies (FL, LA, MD, MN, NE, NJ, NY, OH, VA); Cluster 2 = Centralized and Stable (AL, MS, NH, RI, VT); Cluster $3=$ Complex Solutions and Chaotic Environments (AZ, AR, CA, CO, CT, GA, ID, IN, KY, MO, MT, ND, OR, PA, SC, TX, WA, WI); Cluster 4 $=$ Incremental Change in Bureaucratic Environments (AK, HI, NV, NM, NC, OK, WY); Cluster $5=$ Scarce Resources and Slow Change (IA, KS).

The high degree of centralization may contribute to the group's extreme scores on some other variables. For example, being centralized probably facilitates the integration of decisions $(M=4.8)$. Having a smaller centralized agency may also require a relatively higher percentage of professionally trained administrators, resulting in a high score on technocratization $(M=6.0)$.

There may be two explanations for the high score on precedents. First, the group's leadership has been successful, hence their long tenure and their inclination to continue what is working for them. Second, past results are used for benchmarking, a form of control $(M=5.3)$. Vermont's entire 2000 budget request was directed toward making progress in the reduction of critical health problems, such as infant mortality and vehicular injury (Hogan 1999).

Rhode Island, on the other hand, had a lower score than Vermont on resource availability $(M=5.7)$. One possible explanation is that Rhode Island's Department of Health experienced a sharp decrease in percentage of state funding, from 66 percent in 1990 to 44 percent in 1999. The overall effect of changes in funding and other factors resulted in a 13.7 percent drop in total funds from 1998 to 1999 (Nolan 1999). This contrasted sharply with Vermont, where the tobacco settlement and other factors combined to create a 3.1 percent increase in 
annual funding for the fiscal year 2000 (Hogan 1999). Nevertheless, the relatively stable environments of these agencies probably make management of them far simpler than the next group.

TABLE 3 State Configuration Groups and Distances from Centers

\begin{tabular}{|c|c|c|c|c|}
\hline Cluster & State & $\begin{array}{c}\text { Distance } \\
\text { from Center }\end{array}$ & $\mathbf{M}$ & $\mathrm{SD}$ \\
\hline \multicolumn{5}{|c|}{$\begin{array}{l}\text { Cluster 1: } \\
\text { Flexible Agencies } \\
\text { in Unpredictable }\end{array}$} \\
\hline Environments & $\begin{array}{l}\text { Ohio } \\
\text { New Jersey } \\
\text { Maryland } \\
\text { Minnesota } \\
\text { Virginia } \\
\text { Louisiana } \\
\text { Nebraska } \\
\text { Florida } \\
\text { New York }\end{array}$ & $\begin{array}{l}2.17155 \\
2.78459 \\
3.06267 \\
3.15014 \\
3.19170 \\
3.69431 \\
3.75882 \\
3.78102 \\
5.02701\end{array}$ & 3.40242 & 0.799612 \\
\hline \multicolumn{5}{|l|}{$\begin{array}{l}\text { Cluster 2: } \\
\text { Centralized }\end{array}$} \\
\hline & $\begin{array}{l}\text { Alabama } \\
\text { Mississippi } \\
\text { Rhode Island } \\
\text { New Hampshire } \\
\text { Vermont }\end{array}$ & $\begin{array}{l}2.76641 \\
2.84201 \\
3.01637 \\
3.14156 \\
3.56678\end{array}$ & & \\
\hline \multicolumn{5}{|c|}{$\begin{array}{l}\text { Cluster 3: } \\
\text { Complex Solutions } \\
\text { and Chaotic }\end{array}$} \\
\hline & $\begin{array}{l}\text { Colorado } \\
\text { North Dakota } \\
\text { Kentucky } \\
\text { Missouri } \\
\text { Connecticut } \\
\text { South Carolina } \\
\text { Washington } \\
\text { Georgia } \\
\text { Montana } \\
\text { Wisconsin } \\
\text { Idaho } \\
\text { Arizona } \\
\text { Pennsylvania }\end{array}$ & $\begin{array}{l}2.59829 \\
2.62804 \\
2.70010 \\
2.80874 \\
2.94648 \\
2.98177 \\
3.05848 \\
3.06343 \\
3.08840 \\
3.18027 \\
3.37641 \\
3.40061 \\
3.40446\end{array}$ & & \\
\hline
\end{tabular}




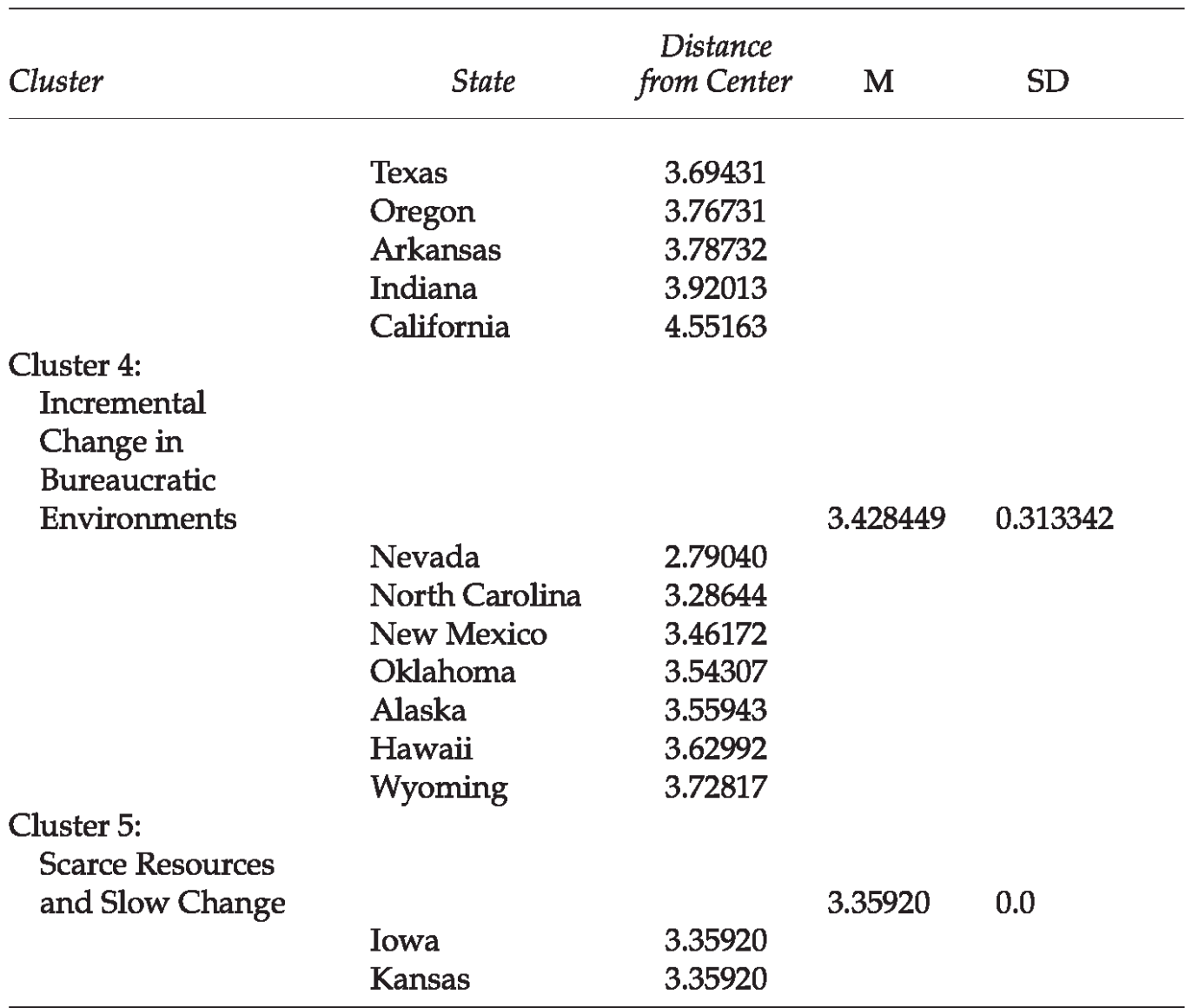

\section{CONFIGURATION 3: COMPLEX SOLUTIONS AND CHAOTIC ENVIRONMENTS}

Complex Solutions and Chaotic Environments was by far the largest configuration with 18 members, or 44 percent of the total states evaluated. This cluster's members contrast sharply with the previous cluster's, which faced dynamic environments, had complex structures, used sophisticated information systems, and were relatively decentralized. They also had the high mean scores on environmental dynamism and heterogeneity, structural complexity, integration of decision making, conscious strategic analysis, and delegation of operating authority.

The Texas Department of Health's strategic plan (The Strategic Planning Steering Committee 1998, 13) pointed to the effect of environmental dynamism, stating, "The role and scope of public sector social services are being reshaped by shifts in citizen expectations of government." The California Department of Health Services (CDHS) was also seeking to "deal effectively with rapidly changing circumstances" (Belshé 1998, 1). These statements are representative of the general tone of the planning documents in this cluster.

One possible explanation for why the perceptions of the environment are problematic in this cohort is the degree of futurity. California and Texas make mention of the changing demographics of their communities. Texas, in particular, is looking at trends up to the year 2030. By 2008, it is projected that no one race will constitute a simple majority in that state (The Strategic Planning Steering Committee 1998). Because the lack of health insurance disproportionately affects minorities, their concerns are well founded.

This configuration is among the most rigorous in their consciousness of strategic analysis. For example, in Kentucky, the plan took 5 years to develop and was, in effect, "written by 2,500 Kentuckians" (Stumbo 1998, 5). Commensurate with the amount of planning was the size and complexity of these agencies. On average, they had five levels of management (hierarchy) starting with the leaders, and the mean span of control was only 3.8 
positions per manager. Another aspect of having tall organizational structures is the necessity of decentralizing the authority to act among various layers of management (centralization, $M=3.9$ ). These agencies scored relatively low on centralization, as indicated in California: "Building upon department coalitions with community-based organizations will be the foundation of our staff and program development. Our dedicated workforce is on the front lines of public health each day. Our success depends upon their ... initiative to solve problems" (Belshé 1998, p. 3). Because the CDHS does not directly provide services within the community, effective scanning $(M=5.1)$ and support of local health agencies (delegation, $M=5.2)$ are important organizational characteristics. This organizational structure is a stark contrast to that used in the next configuration.

\section{CONFIGURATION 4: INCREMENTAL CHANGE IN BUREAUCRATIC ENVIRONMENTS}

The Incremental Change in Bureaucratic Environments configuration was composed of 7 states (17 percent), most of which were located in the Western United States. The variables that most influenced this configuration were the tenure of their leaders, which was the second longest, and their reliance on precedents. This cluster's scores on environmental scanning and controls associated were relatively low. The lack of leaders with technical expertise is also reflected in the lack of innovation or adaptability of this configuration. A reliance on precedents was clearly observed among this cluster's members. Therefore, these organizations tended to react to significant environmental events and usually apply previously proven solutions to adapt.

North Carolina was very typical of these agencies, as evidenced by it close proximity to the cluster's center. This health agency's agenda was driven by its budget rather than by any assessment of needs. The strategic planning documentation was entirely subordinate to the budgeting process and any strategic changes were footnoted. This phenomenon is reflected in the agencies' high reliance on precedent and low scores on innovation, adaptiveness, and futurity of decision making. A potential consequence of this type of system is that initiating new programs or terminating programs that are no longer necessary is very difficult.

\section{CONFIGURATION 5: SCARCE RESOURCES AND SLOW CHANGE}

The Scarce Resources and Slow Change configuration was composed of just two states: Iowa and Kansas. The distance from this cluster's center was the farthest from every other configuration. Therefore, this cluster was the most idiosyncratic of those studied.

The Scarce Resources and Slow Change group appeared to inhabit environments that were relatively hostile. Scanning for opportunities may not have been fully developed because of their lack of resources. The lack of information probably inhibits their ability to engage in meaningful conscious strategic analysis. Another explanation for these agencies' reactive strategies may be the short tenure of their leaders and the lack of technical training. In addition, members of this cluster do not seem to seek out the opinions of key stakeholders, as evidenced by a low average score on multiplexity. Without this type of analysis, innovation may be less effective and, over time, an increased reliance on precedents may result.

Scanning in the Scarce Resources and Slow Change states was most obvious by its absence. Although other state agencies, such as Kentucky, were making consumer, provider, and legislator involvement a key component of their visions, this cluster of states made only passing references to addressing consumer needs. Besides their inability to build external relationships, these agencies also had trouble communicating internally, as indicated by their low scores on communication and integration of decision making. A survey of Iowa Department of Public Health Employees indicated that "staff shared the concern with nonstaff over communication and information, it was their second most frequently cited item." Respondents to the survey also "expressed frequent and considerable frustration with mismanagement: inconsistent direction, lack of trust and support, moving deadlines, etc." (Gleason 1999, 7). These concerns are consistent with low scores on items such as control and consciousness of analysis.

All of these other concerns, however, were secondary in light of the perceived lack of funding (the single most cited problem in the Iowa survey). The raters gave this configuration a 1.8 on munificence and resource 
availability out of a possible 7, by far the lowest among any group. Taking the lack of resources and overall poor management together, these states are facing far more serious problems than most others.

\section{DISCUSSION}

In strategic terms, the configuration labeled Flexible Agencies in Unpredictable Environments has progressed the furthest into the organizational planning paradigm. This is reflected in their emphasis on analysis, planning, innovation, and the ability to adapt. In contrast, the agencies labeled Scarce Resources and Slow Change appear to be doing very little strategic planning. These states had the lowest average scores on several strategy-making variables including conscious analysis, innovation, and adaptive capacity.

The configuration engaging in the second highest amount of strategy making is the Centralized and Stable group. This configuration is generally composed of smaller agencies, engaging in fewer public health activities. One way of viewing these agencies is that they have matured. Not unlike cash cows in other industries, these agencies perform a valuable function relatively well and require little maintenance. For example, in Vermont, the vast majority of residents' health needs are met through the private insurance market, thereby reducing the need for safety-net programs and leaving the state health agency to focus primarily on assessment and policy development functions rather than assurance. However, other states with larger uninsured or more diverse populations may not fare well under this model.

State agencies facing dynamic environments while building large public health infrastructures are labeled Complex Solutions and Chaotic Environments. These agencies are generally more focused on organizational characteristics rather than strategic planning functions. Nevertheless, they do engage in a fair amount of longrange planning and, from a management research point of view, are moving toward more contemporary organizational forms.

Incremental Change in Bureaucratic Environments appears to be the second least desirable configuration from a strategy perspective. Their limited scanning and heavy reliance on precedents inhibits analysis and, in turn, their ability to innovate. Furthermore, by attempting to match their organizational structure rather than their strategies to the environment, they may be reducing their ability to adapt. Given their limited resources and environmental hostility, in the future these agencies may desire the slow change that characterizes the lower end of the continuum. Therefore, from the strategy perspective, the agency configurations are distinct in several meaningful dimensions. Agency leaders, their stakeholders, and health care researchers can use such information to complement their current understandings and identify areas that need more exploration.

\section{CONCLUSIONS, LIMITATIONS, AND AREAS OF FUTURE RESEARCH}

This article presents a taxonomy for grouping state health agencies on the bases of their environmental characteristics, strategic planning capabilities, and organizational constructs. Management theorists assume that organizations that are most skillful in adapting to changing environments - and adjusting their strategies and structures accordingly_will be most successful in achieving their goals. The results of this research provide valuable information to public health practitioners and management researchers.

The results of this study indicated that five distinct state health agency gestalts existed during the period examined. For the leadership of these organizations, this taxonomy provides new and more extensive insights into organizational forms and managerial issues than previous research based on one or two dichotomous variables. These findings can be applied in two ways. First, agency planners can compare their configuration with state agencies they perceive to be superior performers and target specific areas of improvement. Alternatively, the configuration approach to thinking about organizations allows leaders to create new types of organizational forms that can address a rapidly changing public health environment.

For management researchers, this study demonstrates that configuration research designs can be meaningfully applied in the public sector. The study attempted to exhaustively evaluate a narrowly defined group of organizations and ultimately examined 82 percent of all state agencies, thus advancing the generalizability of the 
approach. For public health researchers, these results provide a set of organizational types that can be compared with measures of core public health function capacities to determine which configurational elements are most important to the field. Nevertheless, there are limitations to this study that, if overcome, would potentially create an enhanced picture of health agency effectiveness and configuration research.

\section{LIMITATIONS}

There are two limitations that significantly affect the potential utility and reliability of this study's results. With respect to utility, the lack of success metrics by which the configurations, and the organizations that compose them, can be arrayed leaves the question of which configurations are most effective and under what circumstances unanswered. The second significant limitation is the data sources that were used. Scoring data gathered directly from the agencies themselves may create response biases.

Response biases related to the data sources may have taken two forms. The first is that nonrespondent states may have created undetected gestalts, altered existing configuration memberships, or both. Given that several of the measures are related to the amount, quality, and inclusiveness of planning and reporting this is a serious concern. Nevertheless, other measures of potential nonresponse were negative, and the results presented are internally consistent. The second form of response bias that may have affected the scoring was a social desirability bias. Raw data gathered from the state health agencies may have been propaganda or idealistic visions of the future. Therefore, some state scores may have been systematically inflated based on that data. Nevertheless, many states identified significant deficiencies in their current organization configurations with remarkable candor. While these limitations are significant, they also provide opportunities for future research.

\section{FUTURE RESEARCH}

State health agencies face a variety of challenges with numerous measures of success. The degree of importance of any measure is also highly variable, dependent on a state's unique population composition and resources. Systematically evaluating which public health measures are most or least effectively addressed by each configuration could potentially aid agency leaders in developing their strategies and organizing their structures. Alternatively, determining the relationship between configuration variables and leading health measures as outlined in Healthy People 2010 (U.S. Department of Health and Human Services 2000) would aid future researchers in specifying critical organizational elements to include in their studies. In light of recent terrorist attacks, health agencies' preparedness, as measured by the State Capability Assessment for Readiness (Allbaugh 2001), could be compared to organizational configurations to help identify areas for improvement.

Combining the data from this study with previous configuration research could address issues of reliability and validity. Analyzing the nature of their data sources across studies may help determine how much and the directions of bias variances attributable to case studies and organizational data. In terms of validity, testing the stability of configurations across studies would answer questions regarding the generalizability of the configuration methodology. 


\begin{tabular}{|c|c|c|c|}
\hline \multicolumn{4}{|c|}{$\begin{array}{c}\text { APPENDIX } \\
\text { Variable Groups, Numbers, Names, and Definitions }\end{array}$} \\
\hline $\begin{array}{l}\text { Variable } \\
\text { Dimension }\end{array}$ & Number & Variable Label & Definition \\
\hline \multirow[t]{3}{*}{ Environmental } & 1 & Dynamism & $\begin{array}{l}\text { The amount and unpredictability of } \\
\text { change (i.e., the instability) in things } \\
\text { like technology, client wishes, and } \\
\text { competition within the industry } \\
\text { segment. }\end{array}$ \\
\hline & 2 & Heterogeneity & $\begin{array}{l}\text { The differences or complexity in the } \\
\text { services provided and in patient or } \\
\text { customer tastes, and the resulting } \\
\text { differences needed in competitive } \\
\text { tactics (i.e., amount of understanding } \\
\text { and sophistication needed in mar- } \\
\text { keting, administration, delivery } \\
\text { system, etc.). }\end{array}$ \\
\hline & 3 & Munificence & $\begin{array}{l}\text { Appears as steady funding, regulatory } \\
\text { discretion, adequate work force, } \\
\text { sufficient materials, and favorable } \\
\text { demographic trends. The comple- } \\
\text { mentary term used by D. Miller and }\end{array}$ \\
\hline
\end{tabular}

APPENDIX (continued)

\begin{tabular}{|c|c|c|c|}
\hline $\begin{array}{l}\text { Variable } \\
\text { Dimension }\end{array}$ & Number & Variable Label & Definition \\
\hline & & & $\begin{array}{l}\text { Friesen } 1984 \text { is hostility, which } \\
\text { can be thought of the lower anchor } \\
\text { on the scale. }\end{array}$ \\
\hline \multirow[t]{8}{*}{ Structural } & 4 & Scanning & $\begin{array}{l}\text { The amount of tracking and the number } \\
\text { of agency members involved in } \\
\text { scanning the environment in terms } \\
\text { of consumer issues and administra- } \\
\text { tive developments. }\end{array}$ \\
\hline & 5 & $\begin{array}{l}\text { Delegation of } \\
\text { operating } \\
\text { authority }\end{array}$ & $\begin{array}{l}\text { The amount of authority for day-to-day } \\
\text { operational decisions transferred } \\
\text { from top managers to lower level } \\
\text { and middle-level managers. }\end{array}$ \\
\hline & 6 & $\begin{array}{l}\text { Centralization } \\
\text { of strategy- } \\
\text { making } \\
\text { power }\end{array}$ & $\begin{array}{l}\text { The distribution of power to make long- } \\
\text { term, strategic decisions. Is power is } \\
\text { distributed throughout the agency } \\
\text { and decentralized or centralized in } \\
\text { top management? }\end{array}$ \\
\hline & 7 & $\begin{array}{l}\text { Resource } \\
\text { availability }\end{array}$ & $\begin{array}{l}\text { The amount of available labor, materi- } \\
\text { als, capital, facilities, and other re- } \\
\text { sources. This is different from mu- } \\
\text { nificence, which relates to issues } \\
\text { outside the agency's control. }\end{array}$ \\
\hline & 8 & $\begin{array}{l}\text { Management } \\
\text { tenure }\end{array}$ & $\begin{array}{l}\text { Average number of years top managers } \\
\text { have held their positions, measured } \\
\text { to the nearest tenth of a year. }\end{array}$ \\
\hline & 9 & Controls & $\begin{array}{l}\text { The number and scope of systems to } \\
\text { measure performance trends. } \\
\text { Agencies that emphasize manage- } \\
\text { ment information systems, budgets, } \\
\text { and performance appraisal score } \\
\text { high on this variable. }\end{array}$ \\
\hline & 10 & $\begin{array}{l}\text { Internal com- } \\
\text { munication }\end{array}$ & $\begin{array}{l}\text { The ease and fidelity with which all } \\
\text { kinds of information flows through- } \\
\text { out the agency. }\end{array}$ \\
\hline & 11 & $\begin{array}{l}\text { Agency dif- } \\
\text { ferentiation }\end{array}$ & $\begin{array}{l}\text { The degree of differences in goals, ad- } \\
\text { ministration, behavior, operations, } \\
\text { and management style between } \\
\text { units or departments in the agency. }\end{array}$ \\
\hline
\end{tabular}


APPENDIX (continued)

\begin{tabular}{|c|c|c|c|}
\hline $\begin{array}{l}\text { Variable } \\
\text { Dimension }\end{array}$ & Number & Variable Label & Definition \\
\hline \multirow{9}{*}{ Strategy making } & 12 & $\begin{array}{l}\text { Technocrati- } \\
\text { zation }\end{array}$ & $\begin{array}{l}\text { The percentage of staff with profes- } \\
\text { sional qualifications. }\end{array}$ \\
\hline & 13 to 14 & $\begin{array}{l}\text { Spatial } \\
\text { complexity }\end{array}$ & $\begin{array}{l}\text { The breath and depth of the agency } \\
\text { that the leader must manage. A con- } \\
\text { tinuous variable }(Y) \text { created by tak- } \\
\text { ing the log of the number of levels } \\
\text { in the hierarchy }(n) \text { using the average } \\
\text { span of control for the widest level } \\
\text { as the base }(S) \text { so that } Y=\log _{S} n \text {. }\end{array}$ \\
\hline & 15 & Innovation & $\begin{array}{l}\text { The amount of innovation used in } \\
\text { terms of number and novelty of } \\
\text { new services/products. }\end{array}$ \\
\hline & 16 & $\begin{array}{r}\text { Adaptiveness / } \\
\text { proactiveness }\end{array}$ & $\begin{array}{l}\text { The amount of response by the agency } \\
\text { to external environmental condi- } \\
\text { tions, and the appropriateness with } \\
\text { which and degree to which the } \\
\text { agency attempts to shape its } \\
\text { environment. }\end{array}$ \\
\hline & 17 & $\begin{array}{l}\text { Integration } \\
\text { of decisions }\end{array}$ & $\begin{array}{l}\text { The degree to which actions in one unit } \\
\text { of the agency complement or support } \\
\text { those in other units. }\end{array}$ \\
\hline & 18 & $\begin{array}{l}\text { Conscious } \\
\text { strategic } \\
\text { analysis }\end{array}$ & $\begin{array}{l}\text { The amount of time and thought de- } \\
\text { voted to real or perceived problems } \\
\text { and ways to deal with the problems. }\end{array}$ \\
\hline & 19 & Multiplexity & $\begin{array}{l}\text { The range of factors considered by top } \\
\text { managers when making strategic } \\
\text { decisions. }\end{array}$ \\
\hline & 20 & $\begin{array}{l}\text { Futurity of } \\
\text { decision }\end{array}$ & $\begin{array}{l}\text { The time frame used by the agency in } \\
\text { strategic planning. }\end{array}$ \\
\hline & 21 & Precedents & $\begin{array}{l}\text { The degree to which the agency rethinks } \\
\text { its strategies and the way in which } \\
\text { it will attain its strategies. }\end{array}$ \\
\hline
\end{tabular}

\section{NOTE}

1. For a complete scoring package including cues to scorers, please contact the first author.

\section{REFERENCES}

Aldenderfer, M. S., \& R. K. Blashfield.1984. Cluster analysis. Newbury Park, CA: Sage. Allbaugh, J. M. 2001. State capability assessment for readiness. Washington, DC: Federal Emergency Management Agency. Anderson, P. 1999. Complexity theory and organizational science. Organizational Science 10:216-32. Belshé, S. K. 1998. Strategic plan update: 1998-1999 activities (CA). Report. Sacramento, CA: Department of Health Services.

Bettis, R. A.1996. SMJ 1995 best paper prize to Danny Miller. Strategic Management Journal 17 (7): 503. Brooks, R. G. 1999. Agency strategic plan 1999-00 through 2003-04 (FL). Tallahassee: Florida Department of Health.

. 2000. 1999 year in review (FL). Report. Tallahassee: Florida Department of Health.

Centers for Disease Control and Prevention. 1994. Public health corefunctions-Alabama, Maryland, Mississippi, New Jersey, South Carolina, and Wisconsin, 1993. Retrieved 17 August 1999 from www.cdc.gov/epo/mmwr/preview/mmwrhtml/ 00023572.htm Daft, R. L. 1992. Organization theory and design. 4th ed. St. Paul, MN: West.

Doty, D. H., and W. H. Glick. 1994. Typologies as a unique form of theory building - toward improved understanding and modeling. Academy of Management Review 19(2): 230-51.

Elders, J. 1995. The future of U.S. public health. JAMA 269:2293-94.

Fleishman, E. A., and M. K. Quaintance.1984. Taxonomies of human performance: The description of tasks. Orlando, FL: Academic Press.

Gleason, S. 1999. Strategic plan 2000-2005. Des Moines: Iowa Department of Public Health. 
Halverson, P. K., G. P. Mays, A. D. Kaluzny, and T. B. Richards. 1997. Not-so-strange bedfellows: Models of interaction between managed care plans and public health agencies. Milbank Quarterly 75 (1): 113-38.

Hambrick, D. C.1984. Taxonomical approaches to studying strategy: Some conceptual and methodological issues. Journal of Management 10:27-41.

Handler, A. S., and B. J. Turnock. 1996. Local health department effectiveness in addressing the core functions of public health: Essential ingredients. Journal of Public Health Policy 17 (4): 460-83.

Harrigan, K. R.1985. An application of clustering for strategic group analysis. Strategic Management Journal 6:55-73.

Health Resources and Services Administration. (2001). State profiles. U.S. Department of Health and Human Services. Retrieved 21 September 2001 from http:// stateprofiles.hrsa.gov/CreateQueryIndex.html

Hogan, C. D.1999. The year 2000: A time to assess our past and imagine our future. Report. Montpelier, VT:

Agency of Human Services.

Institute of Medicine. 1988. The future of public health. Washington, DC: National Academy Press.. 2002.

Assuring the health of the public in the 21st century. Retrieved 1 March 2002 from

http://www.iom.edu/IOM/IOMHome.nsf/Pages/Assuring+the+Health+of + the+Public

Law, K. S., C. S. Wong, and W. H. Mobley. 1999. Toward a taxonomy of multidimensional constructs. Academy of Management Review 4:741-55.

McKelvey, B.1975. Guidelines for the empirical classification of organizations. Administrative Science Quarterly 20:509-25.

Meyer, A. D., A. S. Tsui, and C. R. Hinings.1993. Configurational approaches to organizational analysis. Academy of Management Journal 36 (6): 1175-95.

Miles, R. E., and C. C. Snow. 1978. Organizational strategy, structure, and process. New York: McGraw-Hill. Miller, C. A., K. S. Moore, and T. B. Richards. 1993. The impact of critical events of the 1980s on the core functions for a selected group of local health departments. Public Health Reports 108:695-700.

Miller, D.1986. Configurations of strategy and structure: Towards a synthesis. Strategic Management Journal 7 (3): 233-49.

. 1996. Configurations revisited. Strategic Management Journal 17 (7): 505-12. Miller, D., and P. H. Friesen. 1984. Organizations: A quantum view. Englewood Cliffs, NJ: Prentice Hall.

. 1986a. Porter's (1980) generic strategies and performance: An empirical examination with American data_Part 1: Testing Porter. Organizational Studies 7 (1): 37- 55.

. 1986b. Porter's (1980) generic strategies and performance: An empirical examination with American data_Part 2: Performance implications. Organizational Studies 7 (3): 255-61.

Mintzberg, H., and J. Lampel. 2001. Reflecting on the strategy process. In Strategic thinking for the next economy, edited by M. A. Cusumano and C. C. Markides, 33-54. San Francisco: Jossey-Bass.

Nichols, D. P. 1998. Choosing an Intraclass correlation coefficient. SPSS Keywords 67. Nolan, P. A.1999.

Public health in Rhode Island: An epidemiological/economic analysis. Report. Providence, RI: Department of

Health.

Pedhazur, E. J., and L. P. Schmelkin. 1991. Measurement, design, and analysis. Hillsdale, NJ: Lawrence Erlbaum.

Porter, M. E.1980. Competitive strategy: Techniques for analyzing industries and competitors. New York: The Free Press.

Public Health Foundation. 1986. Public health agencies. Vols. 1, 2, and 4. Washington, DC: Author.

Reeves, T. C. 1996. Configurations among health service organizations. Unpublished doctoral dissertation, University of Alabama at Birmingham.

Reeves, T. C., W. J. Duncan, and P. M. Ginter. Forthcoming. Strategic configurations in health services organizations. Journal of Business Research.

Rich, P.1992. The organizational taxonomy: Definition and design. Academy of Management Review 17:75881 .

Rubin, R. J.1988. Supplementary statements. In The future of public health, edited by the Institute of Medicine, 161. Washington, DC: National Academy Press.

Scott, H. D., J. Tierney, and W. Waters, Jr. 1990. The future of public health: A survey of the states. Journal of Public Health Policy 11:296-304. 
Scutchfield, F. D., C. A. Beversdof, S. E. Hiltabiddle, and T. Violante.1997. A survey of state health department compliance with the recommendations of the Institute of Medicine Report, The future of public health. Journal of Public Health Policy, 18(1),13-29.

Scutchfield, F. D., S. E. Hiltabiddle, N. Rawding, and T. Violante. 1997. Compliance with the recommendations of the Institute of Medicine report, The future of public health: A survey of local health departments. Journal of Public Health Policy 18 (2):155- 66.

Shortell, S. M., and E. J. Zajac. 1990. Perceptual and archival measures of Miles and Snow's strategic types: A comprehensive assessment of reliability and validity. Academy of Management Journal 33:817-32.

Simon, H. A. 1996. The science of the artificial. 3d ed. Cambridge, MA: MIT Press. Stoto, M. A., C. Abel, and A. Dievler.1996. Healthy communities: New partnerships for the future of public health. Washington, DC: National Academy Press.

The Strategic Planning Steering Committee. (1998). Strategic plan. Austin: Texas Department of Health. Stumbo, S. 1998. Kentucky Public Health Improvement Plan. Frankfort, KY: Cabinet for Health Services. Sutton, R. I., and B. M. Staw.1995. What theory is not. Administrative Science Quarterly 40:371-84. U.S. Census Bureau. 2000. State and county facts. Retrieved 20 September 2001 from http://www.census.gov/census2000/

U.S. Department of Health and Human Services. 2000. Healthy People 2010.2d ed., Vol. 1. Washington, DC: U.S. Government Printing Office.

Wall, S. 1998. Transformations in public health systems. Health Affairs 17 (3): 64-80. Weick, K. E.1995. What theory is not, theorizing is. Administrative Science Quarterly 40 (3): 385-90. 